US Army Corps

of Engineers

Waterways Expe :ment

Station
Project Report No. 366

University of Minnesota

St. Anthony Falls Hydraulic Laboratory

Minneapolis, MN 55414

Water Operations Technical Support Program

\title{
Oxygen Transfer Similitude for a Vented Hydroturbine
}

by Eric J. Thompson, University of Minnesota

Approved For Public Release; Distribution Is Unlimited

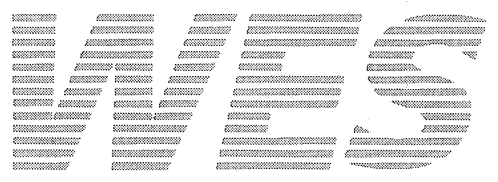

Prepared for Headquarters, U.S. Army Corps of Engineers

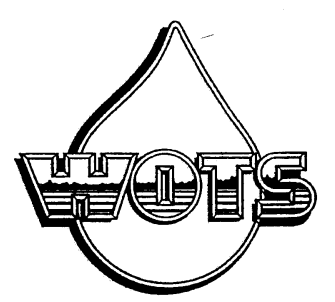




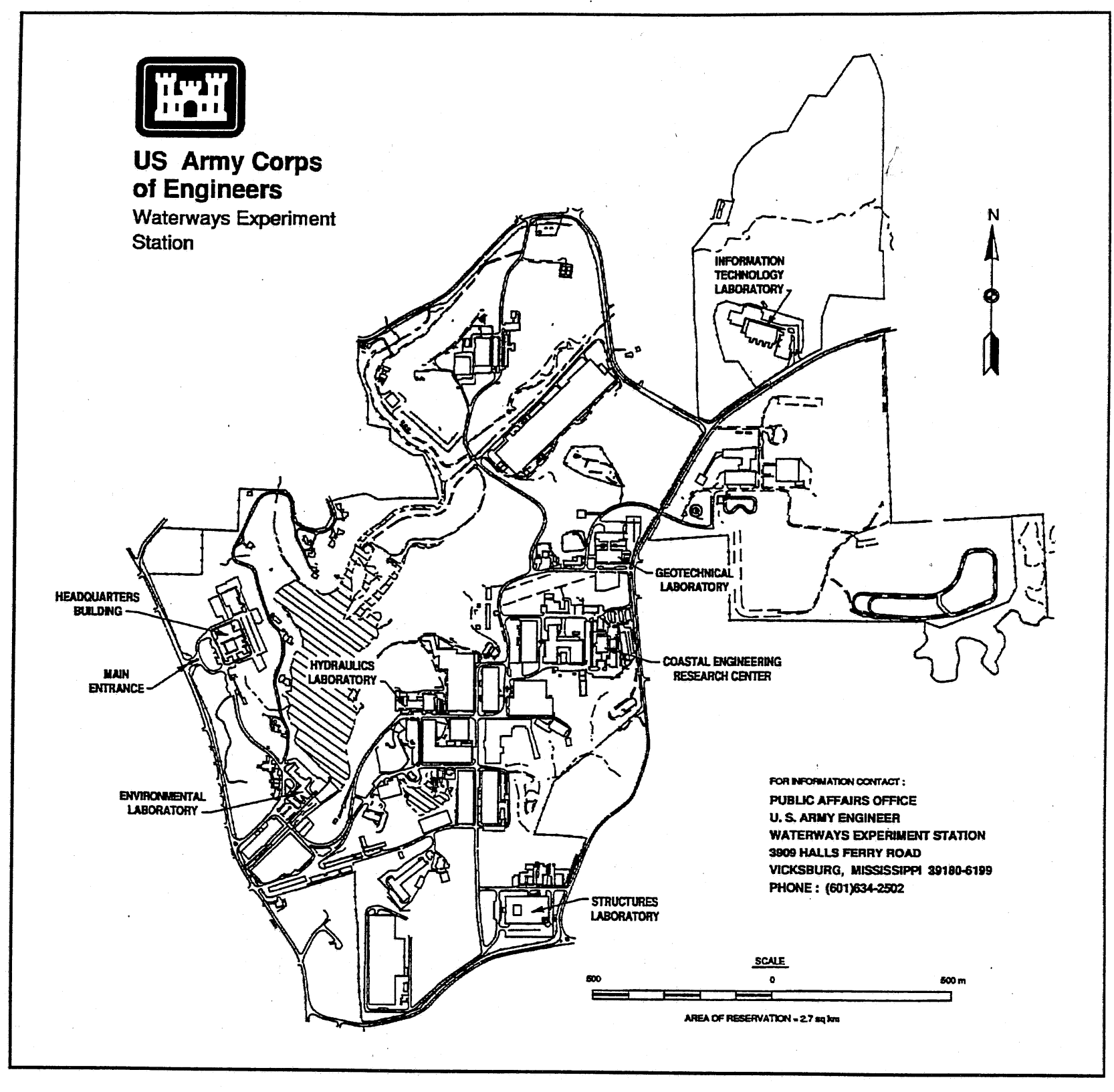

Waterways Experiment Station Cataloging-in-Publication Data

Thompson, Eric J.

Oxygen transfer similitude for a vented hydroturbine / by Eric $\mathrm{J}$.

T3

83 p.: ill. $; 28 \mathrm{~cm}$. - (Miscellaneous
Includes bibliographic references.

1. Water - Dissolved Oxygen - Measurement 2 Turbomachines -

Fluid dynamics. 3. Engineering models - Mathematics 4 W

Aeration - Evaluation I United States Army Corps of Engater -

II. U.S. Army Engineer Waterways Experiment Station. III. Water

Operations Technical Support Program. IV. Title. V. Series:

Miscellaneous paper (U.S. Army Engineer Waterways Experiment

Station); W-94-1.

TA7 W34m no.W-94-1
Contents

Preface $\ldots \ldots \ldots \ldots \ldots \ldots \ldots \ldots \ldots$ vi

Acknowledgements . . . . . . . . . . . vii

Conversion Factors, Non-SI to SI Units of Measurement . . . . . . . vii

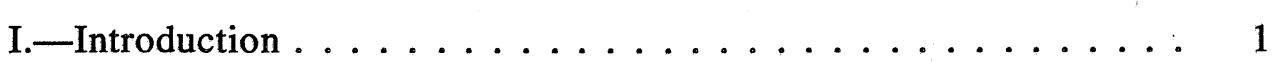

II.-History of Auto-Venting Turbine Research $\ldots \ldots \ldots \ldots \ldots$

III-Data Analysis . . . . . . . . . . . . . . . . . . . . . 13

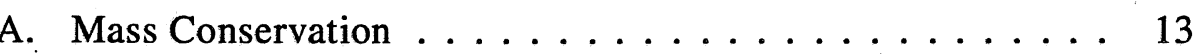

B. Model Studies . . . . . . . . . . . . . . . . . . 15

C. Full-Scale Studies at Norris Hydroplant

IV.-Similitude Theory $\ldots \ldots \ldots \ldots \ldots \ldots \ldots \ldots$

A. Determination of a $\mathrm{K}_{\mathrm{L}}$ Scaling Relationship . . . . . . . 47

B. Development of a Scaling Criterion for Specific Surface Area 51

C. Contact Time $\ldots \ldots \ldots \ldots \ldots \ldots \ldots \ldots \ldots \ldots$

D. Similitude Relation .................. 55

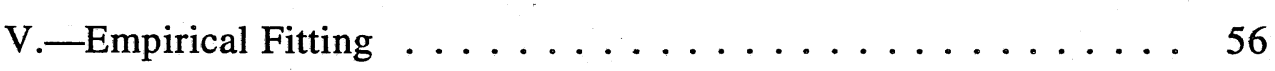

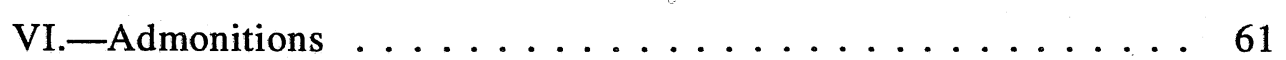

VII.-Calculation Procedure for the Prediction of Full-Scale Oxygen Transfer from Turbine Model Data . . . . . . . . . . . . 66

VIII.-Conclusions and Recommendations . . . . . . . . . . 74

References . . . . . . . . . . . . . . . . . 80

Appendix A. Norris Unit 2 Aeration Test Data $\ldots \ldots \ldots \ldots \ldots$ A1

Appendix B. TVA Model Test Index $\ldots \ldots \ldots \ldots \ldots \ldots$ B1

Appendix C. List of Symbols ................ C1

SF 298 


\section{$\underline{\text { I. Introduction }}$}

Currently there is much emphasis placed upon water quality and maintaining water quality parameters in our freshwater hydrosphere. One of the most widely cited parameters is that of dissolved oxygen concentration (DO). DO is often used as an indicator of the quality of water for use by humans as well as habitat for aquatic flora and fauna, and is maintained by many natural chemical and biochemical processes which either increase or decrease local oxygen concentrations. Respiration by aquatic life serves to reduce DO, as does biodegradation of organic material in the sediments, along with a host of other oxygen consuming chemical reactions. Photosynthesis by aquatic plant life can be a significant source of oxygen to a water body, as can oxygen mass transfer with the atmosphere. In nature these processes result in balanced DO concentrations, allowing for seasonal changes, in surface waters.

Large impoundments of water, such as those found behind hydropower facilities, upset this delicate balance and can have severe effects on water quality. As illustrated by Figure 1.1, spillways withdraw well-mixed surface waters from reservoirs where DO concentrations are high, and toxins, metals, and high nutrient concentrations (symptoms of low DO) are low. Spillways are also very effective aerators, enhancing DO levels by exposing large surfaces of turbulent water to the atmosphere, thus restoring the environment (in terms of oxygen transfer) for the river reach that was made into a slow moving reservoir. 


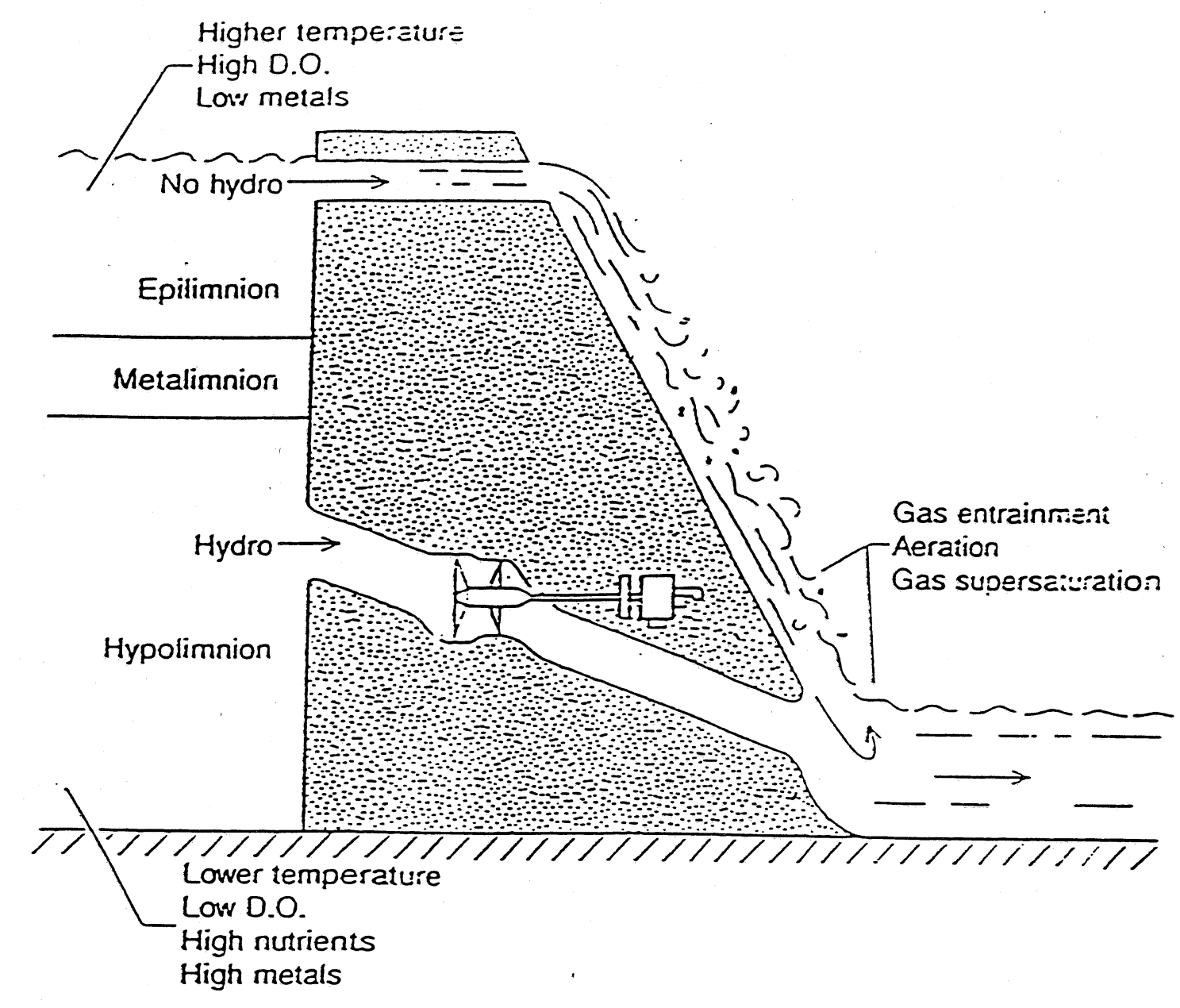

Figure 1.1 Water quality changes due to hydropower operation (Arndt and Gulliver, 1989)
Turbine intakes, however frequently release water from the hypolimnion of reservoirs; where, due to thermal (density) stratification, DO concentrations are often quite low. Thermal stratification occurs in the summer months as solar radiation is absorbed as heat by surface waters, causing density differences in reservoir depth profiles. Typically a reservoir will separate into two distinct levels, the epilimnion, a surface layer of warm, less dense water, and the hypolimnion, a deeper level of relatively cool water, with some intermediate levels collectively called the metalimnion. Because of continued exposure to the atmosphere, and relatively high levels of photosynthesis, DO concentrations in the epilimnion are often near saturation (Cole, 1983). However, because of density stratification between the separate levels and the corresponding reduction in turbulent transport, oxygen transfer to lower reservoir levels may be limited. In areas where hypolimnetic oxygen demand exceeds oxygen replenishment, as is the case in many hydropower reservoirs, DO levels may drop to anoxic (zero DO) conditions.

The concerns for low DO associated with hydroelectric installations primarily involve the preservation of aquatic habitat. Under anoxic conditions, several problems may develop which endanger the lives of fish and other aquatic lifeforms; trace metals and nutrients may be released from sediments, high concentrations of hydrogen sulfide may result from anaerobic biodegradation, and the $\mathrm{pH}$ of the water body may drop (Wilhelms, 1987). Dissolved oxygen concentrations approaching zero will create extensive mortality of fish and other components of the aquatic biota. The 
impacts of poor quality water discharges can extend for tens of river miles downstream of hydroelectric reservoirs. For this reason there is significant interest in alleviating the downstream impacts of these hydroelectric releases.

To reduce or eliminate the problems associated with low DO, the U.S. Army Corps of Engineers (USACE), the Tennessee Valley Authority (TVA), the Alabama Power Company (APC), the U.S. Bureau of Reclamation, and others (March et al, 1992) have been researching various means of increasing DO concentration in hydroelectric tailwaters. One of the most attractive techniques currently being investigated is the auto-venting turbine (AVT)

An auto-venting turbine is a hydroturbine that has pressure relieving ports which are open to the atmosphere. When operating at low flows, strong negative pressures which may be damaging to the turbine are relieved by allowing air to enter the turbine draft tube. Because it is not necessary to inject the air using pumps or compressors, turbines which operate this way are said to be auto-venting (Waldrop, 1992).

In most Francis and Kaplan style turbines there exists an apparatus called a vacuum-breaker assembly which allows air to enter the turbine draft tube, usually at the runner nose cone, for purposes of relieving strong negative pressures which can lead to cavitation and draft tube surging. A side effect of this air venting is that a substantial amount of mass transfer occurs between the water in the draft tube and the oxygen in the air. Tests performed at several hydropower facilities by the Tennessee Valley Authority and the Alabama Power Company have shown that tailwater dissolved oxygen levels may be increased by as much as $2 \mathrm{mg} / \mathrm{l}$ over that of the reservoir headwater by atmospheric venting through the vacuum-breaker valve (Wilhelms et al, 1987).

In areas where hydroelectric discharges have depressed levels of dissolved oxygen, facilities may be operated under conditions where the turbines naturally aspirate tailwaters to improve downstream DO. Unfortunately, because most vacuumbreaker systems use automatic cam-operated valves which are only open at lower gate settings, venting occurs only at low discharges (Bohac \& Ruane, 1990). Furthermore, adding air tends to reduce the water flow through turbines, resulting in losses in power production and in some cases reduction in operating efficiencies. As a result, AVT research has focused on improving the airflow and oxygen transfer through vented hydroturbines while retaining operating performance.

Since many of the hydropower projects which are operated in the United states are nearing the end of their useful lifetimes, and many newer hydroelectric projects need to be relicensed by the year 2000 (Bohac \& Ruane, 1992) recent efforts have gone beyond testing simple alterations on existing Francis runners. 
TVA has initiated a research program including the construction of several model and full-scale turbine runners which allow for variations in design that retrofit turbine runners simply could not provide. Previous tests had been performed on fullscale Francis runners modified by adding vents and baffles. The aeration performance of these retrofit turbines suggested that a newly designed auto-venting turbine runner may result in greatly improved aeration efficiencies.

The process of hydroturbine runner creation involves a theoretical design with consideration given to initial performance guidelines. In a relatively new field, such as vented oxygen transfer, new runner development typically incorporates a scale model. Performance testing on the turbine model can be used to provide insight into the full-scale turbine runner. While turbine similitude, the scaling of hydraulic test results between geometrically similar turbines of different sizes, is an old and relatively standardized process, current similitude theory does not provide for mass transfer and the scaling of this phenomenon between models and full-sized installations. As a result it is difficult to predict the oxygen transfer performance of field scale installations from model operational data.

One component of the research comprising the AVT project has been the development of scaling criteria for the auto-venting turbine under various venting configurations. It is the purpose of this thesis to develop a similitude relationship for the gas transfer that occurs in an auto-venting turbine with specific reference to scaling between a homologous turbine model and a full-size installation, regardless of the turbine operating conditions. The relation is developed with existing theories of air-water mass transfer, bubble hydrodynamics, and turbine hydrodynamics. Data from TVA's Norris model and the full-scale installation, the only model/full-scale data set currently available, will be used to empirically fit and test the similitude theory. 


\section{Conclusions and Recomendation}

The similitude relationship has been developed using existing, well established theories to describe conditions within a turbine draft tube with respect to bubble behavior and mass transfer. The similitude theory segments three important parameters which have been developed as proportionalities for scaling purposes; the liquid film coefficient, the specific surface area, and the contact time.

Extensive literature reviews and analytical consideration were given to each of the scaling parameters as well as their overall performance in the mass transfer equation. The theory was developed from conservation of mass between bubbles and a surrounding fluid volume with the assumption that the saturation concentration of oxygen remains constant over the integral boundaries. Integration of the mass conservation equation yielded a term called mass transfer efficiency (oxygen transfer efficiency, E) which was logrithmically dependent upon the three previously mentioned parameters.

The parametric relationship for liquid film coeficient, $\mathrm{K}_{\mathrm{L}}$, was developed using the surface renewal theories developed by Levich (1962) and Azbel (1981). Because neither relation was specifically designed to describe $\mathrm{K}_{\mathrm{L}}$ for bubbles in a highly turbulent flow field, both relations were fit with appropriate empirical coefficients resulting in one satisfactory relation describing the liquid film coefficient in the AVT's turbulent bubble-water environment. It was found that $\mathrm{K}_{\mathrm{L}}$ was dependent upon the diffusivity of oxygen in water, the kinematic viscosity of water, and the rotational speed and diameter of the turbine.

The specific surface area term is based upon work done by Hinze (1956) which describes the behavior of bubbles in high shear conditions. The basic relation for bubble size resulting from Hinze's work was combined with the bubble swarm theory of Azbel (1981) to determine a scaling relation for specific surface area dependent upon the gas void fraction, the density and surface tension of the water, and the rotational speed and diameter of the turbine.

A relationship describing a scaling criterion for bubble- water contact time was developed from current turbine similitude theory. It was determined that contact time is dependent only upon turbine rotational speed.

The similitude relation is the result of the insertion and simplification of the proportionalities described above into the mass transfer equation. Because there were many parameters common to each of the proportionalities, the similitude equation simplified into a very simple mathematical relation.

The similitude relation can be used to scale model performance data to a fullscale installation at the same gas void ratio by inserting the known operational 
performance and geometric characteristics of the turbine model and the known properties of water and oxygen for the turbine test conditions. Results for many different full-scale operational settings can be determined by inserting respective terms for the full-scale operation.

\section{For the Norris model/full-scale data, good comparisons have been shown using} the model and the full-scale data within the limits of the model operation as describe above. However, as stated previously, without another model-prototype AVT correlation the similitude relation cannot truly be verified. The familiar similitude theory for the prediction of full-scale efficiency and cavitation from model tests were not developed from one model/full-scale comparison. We should, therefore, see the similitude relationship for oxygen transfer, developed from the Norris model/full-scale comparison with some parametric relationships from the literature, as a first approximation, not as a final answer. Further model/full-scale comparisons may indicate that the exponents or the Cs computation need to be altered, or that the correct parameterization of the tailwater oxygen transfer is required. It is however, believed that these adjustments will be fairly minor and the theory described herein should be nearly universally applicable.

\section{$\underline{\text { Recommendations }}$}

Two significant limitations to the similitude relation are the inability to predict the effective saturation concentration of the gas in the water in the draft tube of the prototype and the inability to determine the size and behavior of the bubbles in the turbulent vertical section of the model draft tube.

The latter problem might be solved by use of high speed photography and laser-doppler measurements of velocity, and hence shear, in the vertical section of the model draft tube. The TVA and the Bureau of Reclamation have undertaken this task on a model of the Grand Coulee turbine and have performed some tests at Colorado State University. Solving the former problem will be more difficult however, due to physical limitations because of model size and construction.

In the past some field tests have been performed using a tracer gas to estimate the gas transfer of a chemical compound other than oxygen. One application of a field test using a tracer gas is the injection of Sulfur-Hexafluoride $\left(\mathrm{SF}_{6}\right)$ into air intakes of auto-venting turbines. Since $\mathrm{SF}_{6}$ is not native to the environment, upstream concentrations are zero. Downstream concentrations can be determined by analyzing water samples, gathered similarily to oxygen samples, using a gas chromatagraph. Tests like this allow for quantification of the impacts of upstream reservoir stratification and downstream baseline transfer due to turbulence at the tailwater boil. (Wilhelms, 1993)

Another tracer gas experiment where a slug of water containing $\mathrm{SF}_{6}$ is added to a reservoir and samples are taken to determine the rate at which gas leaves the 
liquid phase can be coupled with the aforementioned test to determine the effective saturation concentration. The $\mathrm{SF}_{6}$ transfer, in this case, will have virtually no saturation concentration, and comparison of the two tracer tests can be used to determine an equivalent (or effective) saturation concentration. For this type of tracer study, the dilution of the water phase $\mathrm{SF}_{6}$ must also be quantified, requiring the simultaneous release of a conservative tracer such as rhodamine-WT.

If a continuous stream of water containing a known concentration of $\mathrm{SF}_{6}$ was released just upstream of the hydroelectric intake, a reverse transfer test could be performed on the AVT. As air was aspirated into the turbine draft tube, $\mathrm{SF}_{6}$ would transfer out of the liquid phase and into the air bubbles. Because there is no measureable quantity of $\mathrm{SF}_{6}$ in the atmosphere, the concentration in the air bubbles would be very close to zero. Therefore regardless of the pressure changes the bubbles experience throughout their trip through the draft tube, no significant change in concentration of $\mathrm{SF}_{6}$ in the bubble will occur.

Upstream samples may be taken in the draft tube as was performed with oxygen, downstream samples can be gathered from a boat as described earlier, and saturation values can be determined from Henry's law and air and water flow measurements. From these measurements, $\mathrm{SF}_{6}$ transfer efficiency can be determined. Comparing the transfer efficiency of $\mathrm{SF}_{6}$ betwwen the two tracer gas tests will reveal an equivalent (or effective) saturation concentration for the draft tube. Knowing the behavior of the gas as described by Henry's law will allow determination of the effective average pressure occuring in the draft tube. 